Original Research Article

\title{
A study on the prescription pattern of antifungal drugs in the Dermatology Department of a tertiary care teaching hospital in Southern Kerala
}

\author{
Parvathy Gopimohan ${ }^{1}$, Sudha M. J. ${ }^{1 *}$, Rathish T. Pillai ${ }^{2}$, Ramani P. T. ${ }^{1}$
}

${ }^{1}$ Department of Pharmacology,

${ }^{2}$ Department of Dermatology, Azeezia Institute of Medical Sciences \& Research, Kollam, Kerala, India

Received: 11 October 2018 Accepted: 01 November 2018

*Correspondence to:

Dr. Sudha M. J.,

Email: sudhasudhasudha@ gmail.com

Copyright: () the author(s), publisher and licensee Medip Academy. This is an openaccess article distributed under the terms of the Creative Commons Attribution NonCommercial License, which permits unrestricted noncommercial use, distribution, and reproduction in any medium, provided the original work is properly cited.

\begin{abstract}
Background: Skin disorders form $2 \%$ of total Out Patient Department consultations worldwide. But no such data is available from India. Studying prescription pattern is a component of medical audit that help prescribers to provide rational and cost-effective medical care. This study is about the prescription pattern of antifungals in this institution and will help in developing local policies for appropriate use of antifungal drugs. The objective was to study the prescription pattern of antifungals in dermatological diseases.

Methods: This is a retrospective study conducted from $1^{\text {st }}$ June 2017 to $30^{\text {th }}$ November 2017 in Dermatology Department. Prescriptions included all newly diagnosed patients with cutaneous fungal infection of both sex who attended Dermatology OPD. Factors considered were sociodemographic parameters, number of patients with combination and monotherapy, number of single topical agents and Fixed Dose Combination (FDC) details of prescribing indicators.

Results: 1500 prescriptions were analysed; 500 prescriptions were of fungal infection. $40.2 \%$ of the patients were in $18-35$ years age group. There were a greater number of males $(59.6 \%)$ than females $(40.4 \%)$.

Conclusions: The most common oral antifungal used was fluconazole. Terbinafine and clotrimazole were the most commonly used topical agents.
\end{abstract}

Keywords: Antifungal, Drug utilization, Dermatological disease, Prescription pattern

\section{INTRODUCTION}

Skin diseases are common and forms $18^{\text {th }}$ leading cause of health burden worldwide. $2 \%$ of total Out Patient Department (OPD) consultation worldwide are constituted by skin disorders. But no such data is available from India. In this country skin disorders are common and include pyoderma, acne, urticaria, dermatitis, scabies, fungal skin infections, alopecia etc. ${ }^{1,2}$

The drugs that are commonly prescribed in the treatment of skin diseases include antibiotics, antifungals, benzoyl peroxide, steroids, salicyclic acid, anti-histamines, vitamins, minerals and analgesics which usually depends upon prescriber's choice. ${ }^{3}$

According to WHO the rational use of drugs helps in developing standard treatment guidelines, preventing inappropriate drug use, adoption of essential list of drugs, and determining irrational prescription. ${ }^{4}$ The study of prescription pattern is a component of medical audit that helps prescribers to provide rational and cost effective medical care which will be beneficial to patients. ${ }^{5}$ 
In a tropical country fungal infection are quite common. Fungal infections have increased tremendously in the last 3-4 decades due to increased use of broad-spectrum antifungal agents and high prevalence of immune deficiency of immune deficiency states where there is a decrease in natural defenses (HIV/AIDS, diabetes mellitus, use of immunosuppressive drugs like corticosteroids). They can produce a wide variety of fungal infections ranging from superficial skin infection to systemic diseases. Majority of the fungal infections are easily diagnosed and treated. ${ }^{6}$

This study is intended to determine the pattern of dermatological diseases in this locality and to study the prescription pattern of antifungals in this institution. This study will help in understanding antifungal prescription practices and also in developing local policies for appropriate use of antifungal drugs.

\section{METHODS}

The observational, retrospective study was carried out at Azeezia Medical College, Kollam. Data of drugs prescribed were taken from patient's prescription. The study was approved by Azeezia Ethics Committee, Kollam

This study was observational retrospective conducted over 6 months period from June 2017 to November 2017.

Out Patient department in Dermatology in Azeezia Medical College, Kollam, India. All cases in Dermatology OPD was included in study population.

\section{Inclusion criteria}

- Newly diagnosed patients

- Both sex

\section{Exclusion criteria}

- Patients who are already on antifungal treatment

- Admitted in the ward

Duration of the study was 6 months. Convenient sampling method was used while studding.

\section{Data collection}

All necessary and relevant patient information and drugs prescribed were collected from patient's prescription. The data were filled in the proforma prepared which was approved by the Azeezia Ethics Committee. Factors analysed were:

- $\quad$ Sociodemographic parameters (age, sex, occupation)

- The disease encountered and number of patients in each group

- Number of patients who received combination antifungal therapy (oral + topical) and monotherapy during the entire study period.
- The various single topical agents and fixed dose combinations used and the number of encounters with each agent.

- The various oral agents and the number of encounters with each agent

- Details of prescribing indicators:

- $\quad$ The average number of drugs prescribed per encounter

- $\quad$ The average number of antifungals prescribed per encounter

- $\quad$ The average number of systemic antifungal drugs prescribed per encounter

- $\quad$ The average number of topical antifungal drugs prescribed per encounter

- The percentage of encounter with injections

- The percentage of encounters with fixed dose combinations

- $\quad$ The percentage of drugs prescribed by generic name

- The percentage of drugs prescribed from National list of Essential Medicine (NLEM)

\section{Statistical data analysis}

The data was entered into Microsoft excel and results were represented as frequencies and percentage.

\section{RESULTS}

The result of this study shows that out of 1500 prescriptions studied, 500 prescriptions were of fungal infection. Data was collected from outpatient department of Azeezia Medical College, Kollam.

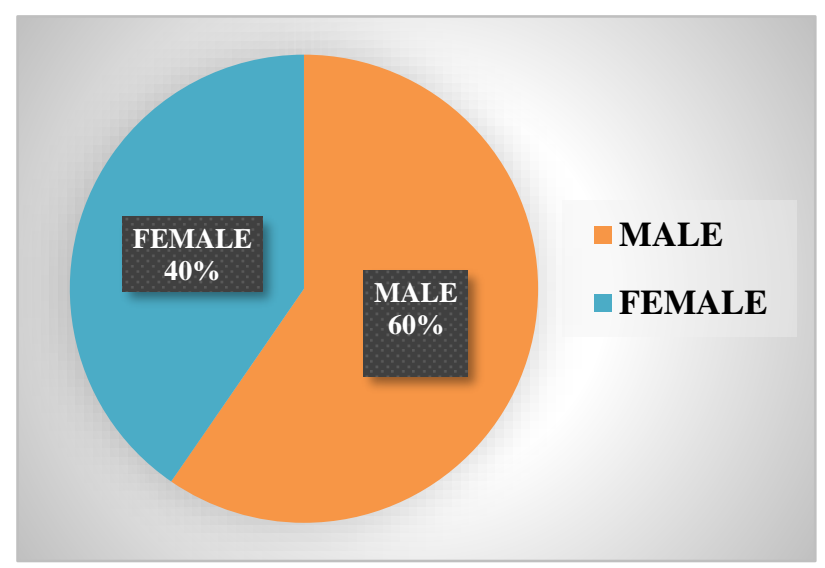

Figure 1: Number of patients in each sex groups.

Figure 1 shows the percentage of patients in each sex groups. Out of 500 prescriptions, 298 (59.6\%) were of males and $202(40.4 \%)$ of females. There was high percentage of males than females and the male to female ratio of our study was $1.47: 1$.

When age distribution was analysed, maximum patients 
belonged to age group 18-35 years which was 201 (40.2\%). This was followed by 132 patients in 0-18 age group which was $26.40 \%$ Minimum patients were in age group 36-55 years that was 122 patients out of 500 $(24.40 \%)$. It was found that the patients in two extreme age groups were lesser compared to the group of maximum numbers. From this study we observed that, as the age increases, there was progressive increase in number of patients till 35 years and then there was a decrease in number of patients. Data is represented in Table 1.

Table 1: Age Distribution of patient.

\begin{tabular}{|lll|}
\hline $\begin{array}{l}\text { Age groups } \\
\text { (years) }\end{array}$ & $\begin{array}{l}\text { Number of patients } \\
(\mathbf{n}=\mathbf{5 0 0})\end{array}$ & $\begin{array}{l}\text { \% of patient in } \\
\text { each group }\end{array}$ \\
\hline $0-18$ & 132 & $26.40 \%$ \\
\hline $18-35$ & 201 & $40.2 \%$ \\
\hline $36-55$ & 122 & $24.40 \%$ \\
\hline
\end{tabular}

In Table 2, more than half of the patients (54\%) were students which accounts for 270. This was followed by home- makers $(24.2 \%)$ which constituted about 121 . The remaining patients belonged to the occupied group which was $82(16 \%)$ and others came around $27(5.4 \%)$. The maximum number of patients belonged to the group of students.

Table 2: Distribution of patients with occupation.

\begin{tabular}{|lll|}
\hline Occupation & $\begin{array}{l}\text { Number of patients } \\
(\mathbf{N}=\mathbf{5 0 0})\end{array}$ & $\begin{array}{l}\text { Percentage } \\
\text { distribution }\end{array}$ \\
\hline Occupied & 82 & $16.4 \%$ \\
\hline Home makers & 121 & $24.2 \%$ \\
\hline Students & 270 & $54 \%$ \\
\hline Nil & 27 & $5.4 \%$ \\
\hline
\end{tabular}

Out of 500 prescriptions studied, 102 patients received monotherapy which was around $20.4 \%$. Around $79.6 \%$ (398) patients received combination therapy which is represented in table 03 . Combination therapy included oral and topical therapy.

Table 3: Type of therapy taken by patients.

\begin{tabular}{|lll|}
\hline $\begin{array}{l}\text { Type of } \\
\text { therapy }\end{array}$ & $\begin{array}{l}\text { Number of patients } \\
(\mathbf{N}=\mathbf{5 0 0})\end{array}$ & $\begin{array}{l}\text { Percentage } \\
\text { of patients }\end{array}$ \\
\hline Monotherapy & 102 & $20.4 \%$ \\
\hline $\begin{array}{l}\text { Combination } \\
\text { therapy }\end{array}$ & 398 & $79.6 \%$ \\
\hline
\end{tabular}

Clotrimazole and Terbinafine was the most commonly prescribed drugs in single topical agents which is $29 \%$. This is followed by Ketoconazole (23.2\%) and Luliconazole $(20 \%)$ and Miconazole $(0.6 \%)$.Among the fixed drug combinations Clotrimazole and Betamethasone $(17.4 \%)$ were used Terbinafine is most commonly used oral formulation $(48.8 \%)$ followed by Fluconazole (32\%).These data are represented in Table 4.
Table 4: Utilization pattern of dermatological drugs.

\begin{tabular}{|c|c|c|}
\hline Single topical agents & $\begin{array}{l}\text { Fixed drug } \\
\text { combinations }\end{array}$ & Oral agents \\
\hline Clotrimazole (29\%) & \multirow{5}{*}{$\begin{array}{l}\text { Clotrimazole } \\
\text { with } \\
\text { betamethasone } \\
(17.4 \%)\end{array}$} & \multirow{5}{*}{$\begin{array}{l}\text { Terbinafine } \\
(48.8 \%) \\
\text { Fluconazole } \\
(32 \%)\end{array}$} \\
\hline Terbinafine (29\%) & & \\
\hline $\begin{array}{l}\text { Ketoconazole } \\
(23.2 \%)\end{array}$ & & \\
\hline Luliconazole (20\%) & & \\
\hline Miconazole $(0.6 \%)$ & & \\
\hline
\end{tabular}

Regarding WHO specified drug use indicators as shown in Table 5. Out of 1500 prescriptions, 500 were of antifungals. The other commonly co-prescribed drugs were antihistamines, topical steroids and vitamins. Average number of drugs prescribed per encounter is 3.12. Average number of antifungals prescribed per encounter is 2. Average number of systematic antifungal drugs prescribed per encounter is 1 . Percentage of encounters with injections were $0.4 \%$. Percentage of encounters with fixed dose combination are $17.4 \%$. Percentage of drugs prescribed from WHO-EML were $33.08 \%$. 66.92\% of drugs were from NLEM. Data represented in Table 5.

Table 5: Details on prescribing indicators.

\begin{tabular}{|ll|}
\hline Indicators & Numbers \\
\hline $\begin{array}{l}\text { Average number of drugs prescribed per } \\
\text { encounter }\end{array}$ & 3.12 \\
\hline $\begin{array}{l}\text { Average number of antifungal prescribed } \\
\text { per encounter }\end{array}$ & 2 \\
\hline $\begin{array}{l}\text { Average number of systematic antifungal } \\
\text { drugs prescribed per encounter }\end{array}$ & 1 \\
\hline $\begin{array}{l}\text { Average number of topical antifungal } \\
\text { drugs prescribed per encounter }\end{array}$ & 1.10 \\
\hline Percentage of encounters with injections & $0.4 \%$ \\
\hline $\begin{array}{l}\text { Percentage of encounters with fixed dose } \\
\text { combinations }\end{array}$ & $17.4 \%$ \\
\hline $\begin{array}{l}\text { Percentage of drugs prescribed from } \\
\text { WHO EML }\end{array}$ & $33.08 \%$ \\
\hline $\begin{array}{l}\text { Percentage of drugs prescribed from } \\
\text { NLEM }\end{array}$ & $66.92 \%$ \\
\hline
\end{tabular}

\section{DISCUSSION}

Skin diseases are one of the commonly encountered medical conditions in the outpatient department. Commonly encountered skin conditions in India are eczema, dermatitis, urticaria, fungal skin infections, acne etc. Skin diseases have a serious impact on people's quality of life in developing countries; more in India where climate, socioeconomic status, religions and customs are widely varied in different parts of the country. ${ }^{7}$

The present study was an observation study conducted with Department of Dermatology after obtaining permission from Azeezia Ethics Committee.1500 patients were assessed out of which 500 were of fungal infection. 
As per table 1, Out of total enrolled patients with fungal infections of skin, most common age group (40.2\%) was 18-35 years. This finding were in accordance with the studies conducted by Pathak et al. $^{8}$ In another study conducted by Vineeta et al, in Belgaum, $71.84 \%$ of patients were in the age groups of 18-75 years. This includes new as well as follow up patients. ${ }^{9}$

Total number of males and females among all patients were $298(59.6 \%)$ and $202(40.4 \%)$ respectively. The findings were similar to the study conducted by Rajathilagam T. which showed $61 \%$ of the patients were men and $39 \%$ were women. ${ }^{10}$

Most of the patients of fungal infections were students followed by homeworkers (housewife and retired person). Andrea carried out a study also showed that most of the patients were homemaker. ${ }^{11}$

Most of the fungal infections can be managed with topical therapy alone. However, to increase cure rate, topical and systematic medications were often combined. In this study, $79.6 \%$ of patients received combination of topical and systematic therapy. Our findings were similar to the study conducted by Minocha were mostly treated with combination of oral as well as topical antifungal agents. ${ }^{12}$

This study showed that Terbinafine (48.8\%) was the most commonly prescribed oral antifungal. Rajathilagam conducted a study also demonstrated that fluconazole was the most commonly used oral antifungal agent. ${ }^{10}$

In this study, most commonly prescribed topical antifungal agent was clotrimazole and Terbinafine (29\%), followed by Ketoconazole (23.3\%). Rajathilagam T. conducted a study showed that Eberconazole (45\%) and clotrimazole $(31 \%)$ followed by Terbinafine were noted to be the frequently prescribed topical antifungal drugs. ${ }^{10}$

As per Table 5, average 3.12 drugs per encounter were prescribed. Vegada BN conducted a study showed that average 3.39 drugs per encounter were prescribed. ${ }^{7}$

\section{CONCLUSION}

Our study shows that most common oral antifungal drug and topical antifungal drug were Clotrimazole and Terbinafine respectively. Combination antifungal therapy was more commonly used than monotherapy.

Funding: No funding sources

Conflict of interest: None declared

Ethical approval: The study was approved by the Institutional Ethics Committee

\section{REFERENCES}

1. Hay RJ, Johns NE, Williams HC, Bolliger IW, Dellavalle RP, Margolis DJ, et al. The Global Burden of Skin Diseases: An analysis of the prevalence and Impact of skin conditions. J Investi Dermatol. 2014;134:1527-34.

2. Gangadharan C, Joseph A, Sarojini PA. Pattern of skin diseases in Kerala. Ind J Dermatol Venereol Leprol. 1976;42:49-51.

3. Bijoy KP, Vidyadhar RS, Palak P, Chintan SP, Atmaram PP. Drugs prescribing and Economic Analysis for Skin Diseases in Dermatology OPD of an Indian Tertiary Care Teaching Hospital: A period Audit. Ind J Pharm Prac. 2012;5:28-33.

4. Tikoo D, Chopra SH, Kaushal S, Dogra S. Evaluation of Drug use pattern in Dermatology as a tool to promote Rational Prescribing. J of Med Edu Res. 2011;13:128-31.

5. Sharma R, Khajuria R, Sharma P, Sadhotra P, Kapoor B, Kohli K, et al. Glaucoma therapy: prescribing pattern and cost analysis. JK Science. 2004;6(2):8892.

6. Das K, Basak S, Ray S. A study on superficial Fungal Infection from West Bengal: A Brief Report J Life Sci. 2009;1:51-5.

7. Vegada BN, Kareli BN, Singh AP. Drug utilization study of antifungal agents used in Department of Skin and veneral disease of a tertiary care teaching hospital. Int J Pharm Sci Rev Res. 2015;34(1):118-21.

8. Pathak AK, Kumar S, Kumar M, Mohan L, Dikshit H. Study of Drug Utilization Pattern for Skin Diseases in Dermatology OPD of an Indian Tertiary Care Hospital - A Prescription Survey. J Clin Diagn Res. 2016 Feb;10(2):FC01-5. Available at: http://www.ncbi.nlm.nih.gov/pubmed/27042479 12.

9. Vineeta D, Sharad P, Ganachari MS, Geetanjali S, Santosh S. Assessment of Drug Prescribing Pattern and Cost Analysis for Skin Disease in Dermatological Department of Tertiary Care Hospital: An Interventional Study. J Pharmaco. 2016;4(3):1-6.

10. Rajathilagam T, Sandozi T, Raagopalan V. A study of prescribing pattern of Antifungal Drugs in Hospital. IJBPR. 2012;3(8):968-73.

11. Andrea C, Pires A, Lobato AM, Regina F, Carneiro O. Clinical, epidemiological and therapeutic profile of dermatophytosis. An Bras Dermatol. 2014;89(2):25965.

12. Minocha KB, Bajaj K, Gupta K. A clinic pharmacological study of Out-Patient prescribing pattern of dermatological Drugs in an Indian tertiary Hospital. Ind J Pharmcol. 2000;32:384-5.

Cite this article as: Parvathy $\mathrm{G}$, Sudha MJ, Pillai RT, Ramani PT. A study on the prescription pattern of antifungal drugs in the Dermatology Department of a tertiary care teaching hospital in Southern Kerala. Int J Basic Clin Pharmacol 2019;8:100-3. 